\title{
ULTRA TRAIL PERFORMANCE IS DIFFERENTLY PREDICTED BY ENDURANCE VARIABLES IN MEN AND WOMEN
}

\begin{tabular}{|c|c|}
\hline Journal: & International Journal of Sports Medicine \\
\hline Manuscript ID & IJSM-05-2020-8306-tt.R2 \\
\hline Manuscript Type: & Training \& Testing \\
\hline Key word: & $\begin{array}{l}\text { sex, ultraendurance, maximal oxygen uptake, ventilatory thresholds, } \\
\text { maximal fat oxidation }\end{array}$ \\
\hline Abstract: & $\begin{array}{l}\text { The study aimed to assess the relationship between peak oxygen uptake, } \\
\text { ventilatory thresholds and maximal fat oxidation with ultra trail male and } \\
\text { female performance. } 47 \text { athletes ( } 29 \text { men and } 18 \text { women) completed a } \\
\text { cardiopulmonary exercise test between } 2 \text { to } 4 \text { weeks before a } 107-\mathrm{km} \\
\text { ultra trail. Body composition was also analyzed using a bioelectrical } \\
\text { impedance weight scale. Exploratory correlation analyses showed that } \\
\text { peak oxygen uptake (men: } r=-0.63, p=0.004 ; \text { women: } r=-0.85 \text {, } \\
p<0.001 \text { ), peak speed (men: } r=-0.74, p<0.001 \text {; women: } r=-0.69 \text {, } \\
p=0.009 \text { ), speed at first (men: } r=-0.49, p=0.035 \text {; women: } r=-0.76 \text {, } \\
p=0.003 \text { ) and second (men: } r=-0.73, p<0.001 \text {; women: } r=-0.76 \text {, } \\
p=0.003 \text { ) ventilatory threshold, and maximal fat oxidation (men: } r=- \\
0.53, p=0.019 ; \text { women: } r=-0.59, p=0.033 \text { ) were linked to race time in } \\
\text { male and female athletes. Percentage of fat mass (men: } r=0.58 \text {, } \\
p=0.010 ; \text { women: } r=0.62, p=0.024 \text { ) and lean body mass (men: } r=- \\
0.61, p=0.006 \text {; women: } r=-0.61, p=0.026 \text { ) were also associated with } \\
\text { performance in both sexes. Subsequent multiple regression analyses } \\
\text { revealed that peak speed and maximal fat oxidation together were able } \\
\text { to predict } 66 \% \text { of male performance; while peak oxygen uptake was the } \\
\text { only statistically significant variable explaining } 69 \% \text { of the variation in } \\
\text { women's race time. These results, although exploratory in nature, } \\
\text { suggest that ultra trail performance is differently predicted by endurance } \\
\text { variables in men and women. }\end{array}$ \\
\hline
\end{tabular}

\section{SCHOLARONE Manuscripts}


1

3

4

5

6

7

8

1 Title: ULTRA TRAIL PERFORMANCE IS DIFFERENTLY PREDICTED BY

2 ENDURANCE VARIABLES IN MEN AND WOMEN

3

$4 \quad$ Heading title: Ultra trail performance prediction in men and women 


\section{Abstract}

6

7 The study aimed to assess the relationship between peak oxygen uptake, ventilatory thresholds 8 and maximal fat oxidation with ultra trail male and female performance. 47 athletes $(29$ men and

918 women) completed a cardiopulmonary exercise test between 2 to 4 weeks before a $107-\mathrm{km}$

10 ultra trail. Body composition was also analyzed using a bioelectrical impedance weight scale.

11 Exploratory correlation analyses showed that peak oxygen uptake (men: $r=-0.63, p=0.004$;

12 women: $r=-0.85, p<0.001$ ), peak speed (men: $r=-0.74, p<0.001$; women: $r=-0.69, p=0.009$ ), speed

13 at first (men: $\mathrm{r}=-0.49, \mathrm{p}=0.035$; women: $\mathrm{r}=-0.76, \mathrm{p}=0.003$ ) and second (men: $\mathrm{r}=-0.73, \mathrm{p}<0.001$;

14 women: $\mathrm{r}=-0.76, \mathrm{p}=0.003$ ) ventilatory threshold, and maximal fat oxidation (men: $\mathrm{r}=-0.53$, $15 \mathrm{p}=0.019$; women: $\mathrm{r}=-0.59, \mathrm{p}=0.033$ ) were linked to race time in male and female athletes.

16 Percentage of fat mass (men: $\mathrm{r}=0.58, \mathrm{p}=0.010$; women: $\mathrm{r}=0.62, \mathrm{p}=0.024$ ) and lean body mass

17 (men: $r=-0.61, p=0.006$; women: $r=-0.61, p=0.026$ ) were also associated with performance in both

18 sexes. Subsequent multiple regression analyses revealed that peak speed and maximal fat 19 oxidation together were able to predict $66 \%$ of male performance; while peak oxygen uptake was

20 the only statistically significant variable explaining $69 \%$ of the variation in women's race time.

21 These results, although exploratory in nature, suggest that ultra trail performance is differently 22 predicted by endurance variables in men and women.

24 Keywords: sex, ultraendurance, maximal oxygen uptake, ventilatory thresholds, maximal fat 25 oxidation 
27

\section{Introduction}

Ultra trail races (UT) have become extremely popular in recent years and the physiological and health consequences of performing such demanding efforts have increasingly awaken the interest of the scientific community $[1,2]$. Additionally, trail running has recently been recognized by the World Athletics as a new running discipline hosting its own Trail World Championships [2]. It is therefore of interest for athletes and coaches to identify those factors that play a critical role in performance in order to improve training strategies and competition results. Previous studies have explored possible factors related with race time in trail running races ranging from $21 \mathrm{~km}$ to 75 $\mathrm{km}$ [3-8]. It remains unclear, however, whether the classical physiological variables of endurance running performance (i.e., maximal oxygen uptake, ventilatory thresholds) [9] hold for longer trail running races (i.e., $>100 \mathrm{~km}$ ). Moreover, the abovementioned studies were conducted in male samples and there is lack of investigations comparing performance factors in male and female athletes competing in ultramarathon races [10].

Indeed, controversy remains regarding the importance of running economy (i.e., energy demand for a given velocity of submaximal running) upon trail running performance [11, 12], with some authors reporting a correlation to race time $[8,13]$ while others do not $[4-6]$. In addition, the importance of substrate utilization is being increasingly emphasized to predict endurance performance $[14,15]$. It is well known that human carbohydrate stores are limited and exogenous carbohydrate uptake cannot match utilization rates during prolonged endurance exercise, leading in turn to muscle and liver glycogen depletion and thus fatigue and decreased performance [16]. This has sparked interest into strategies to augment fat oxidation during endurance exercise to preserve endogenous carbohydrate stores $[15,17]$. Yet, no previous research regarding trail running performance factors have examined whether fat metabolism keeps a significant relationship with race time, as it has been demonstrated for Ironman triathlon $[16,18]$. 
53 The main aim of the present study was therefore to investigate whether the classical physiological

54 variables of endurance running performance, as well as maximal fat oxidation capacity, were

55 linked to performance in an UT race. Secondly, we wanted to assess whether the abovementioned

56 relationships varied between male and female participants. Lastly, we were interested in exploring

57 possible associations between body composition and race time. Our hypothesis were: (1) peak

58 oxygen uptake, peak speed and speed at first and second ventilatory thresholds would be related

59 with performance; (2) maximal fat oxidation capacity would be independently associated with

60 performance in male but not in female athletes $[16,18]$. 


\section{Material and methods}

62

\subsection{Participants}

64

Forty seven ultra-endurance athletes (29 men and 18 women) were recruited to participate in the study. This research was developed at the Penyagolosa Trails CSP race in 2019. The track consisted of $107.4 \mathrm{~km}$, starting at an altitude of $40 \mathrm{~m}$ and finishing at $1280 \mathrm{~m}$ above the sea level, with a total positive and negative elevation of 5604 and $4356 \mathrm{~m}$ respectively (Figure 1). Temperature at the start was $17.2^{\circ} \mathrm{C}$ and it ranged between 18 and $10.6^{\circ} \mathrm{C}$ at mid-race $(\mathrm{km} 66)$, and between 20.1 and $1.5^{\circ} \mathrm{C}$ at the finish line. All subjects were fully informed of the procedure and gave their written consent to participate. They were also allowed to withdraw from the study at will. A questionnaire was used to collect demographic information as well as training and competition history. The investigation was conducted according to the Declaration of Helsinki, it obtained the approval from the research Ethics Committee of the XXX (Expedient Number XXX) to be conducted and it met the ethical standards of the International Journal of Sports Medicine [19]. This study is enrolled in the ClinicalTrails.gov database, with the code number XXX (www.clinicaltrials.gov).

** Insert Figure 1 near here **

\subsection{Body composition}

Body Mass Index (BMI), percentage of fat mass $(\% \mathrm{FM})$ and percentage of lean body mass (\%LBM) were evaluated using a bioelectrical impedance weight scale (Tanita BC-780MA, Tanita Corp., Tokyo, Japan). Measurements were performed in a fasted state $(>6 \mathrm{~h})$ with minimal clothing (i.e., running shorts and t-shirt), following the manufacturer's guidelines. The skin and

87 the electrodes were cleaned and dried before testing. 
90

91

92

93

94

95

96

97

98

99

100

101

102

103

104

105

106

107

108

109

110

111

112

113

114

115

116

\subsection{Cardiopulmonary exercise test}

Cardiopulmonary exercise tests (CPET) were performed on a treadmill (H/P/cosmos pulsar, $\mathrm{H} / \mathrm{P} /$ cosmos sports \& medical GmbH, Nussdorf-Traunstein, Germany) between 2 to 4 weeks prior to the race. Participants were asked to attend the laboratory in a fasted state ( $>6 \mathrm{~h})$ and maintain their habitual mixed macronutrient diet the day before the test. Vigorous exercise was not allowed for $48 \mathrm{~h}$ before and no training was permitted for $24 \mathrm{~h}$ before. All these pre-trial standardisation measures were verbally checked with each participant at his/her arrival to the laboratory. Tests were performed in standard environmental conditions (room temperature between $20^{\circ} \mathrm{C}$ and $22^{\circ} \mathrm{C}$ ) within the same time frame (between $16 \mathrm{PM}$ and $18 \mathrm{PM}$ ). Pulmonary $\mathrm{VO}_{2}$ and $\mathrm{VCO}_{2}$ were measured breath-by-breath using an automated online system (Oxycon Pro system, Jaeger, Würzburg, Germany). Gas analysis system was calibrated for ambient temperature and humidity, air flow and $\mathrm{VO}_{2}$ and $\mathrm{VCO}_{2}$ concentrations (with a $4.96 \% \mathrm{CO}_{2}-12.10 \% \mathrm{O}_{2}$ gas mixture) before each testing session according to manufacturer instructions [20]. After a $4 \min$ warm up at $6 \mathrm{~km} \cdot \mathrm{h}^{-}$ 1, CPET protocol started at $8 \mathrm{~km} \cdot \mathrm{h}^{-1}$ and speed was increased $1 \mathrm{~km} \cdot \mathrm{h}^{-1}$ every $2 \mathrm{~min}$. When subjects reached a respiratory exchange ratio $\left(\right.$ RER) $>1.0$ increments of $1 \mathrm{~km} \cdot \mathrm{h}^{-1}$ were induced every minute until voluntary exhaustion. $\mathrm{VO}_{2}$ max values were accepted when a plateau (an increase of $<2 \mathrm{ml} / \mathrm{kg} / \mathrm{min}$ ) or a decline in $\mathrm{VO}_{2}$ was reached despite increasing workloads and an RER above 1.15 was achieved. If this criteria was not met, a $\mathrm{VO}_{2}$ peak value was taken, defined as the highest $\mathrm{VO}_{2}$ measured over a 30 seconds period. First and second ventilatory thresholds $\left(\mathrm{VT}_{1}\right.$ and $\left.\mathrm{VT}_{2}\right)$ were determined using Skinner and McLellan [21] guidelines by two independent researchers. Peak speed $\left(\mathrm{V}_{\text {peak }}\right)$ Speed and percentage of $\mathrm{VO}_{2}$ peak at $\mathrm{VT}_{1}$ and $\mathrm{VT}_{2}\left(\mathrm{~V}_{\mathrm{VT} 1}, \mathrm{~V}_{\mathrm{VT} 2}, \% \mathrm{VT}_{1}\right.$ and $\% \mathrm{VT}_{2}$ ) were retained for statistical analysis. Subsequently, $\mathrm{VO}_{2}, \mathrm{VCO}_{2}$ and ventilation data were averaged over the last $60 \mathrm{~s}$ of each 2-min stages and stoichiometric equations described by Frayn [22] were used to calculate fat oxidation rates with the assumption that urinary nitrogen excretion was negligible. Fat oxidation rates were then plotted against the relative exercise intensity $\left(\% \mathrm{VO}_{2}\right.$ peak $)$ and a third-degree polynomial regression was used to determine maximal fat oxidation (MFO) and the exercise intensity eliciting MFO (FAT $\left.\mathrm{Fax}_{\max }\right)$ for each participant [23]. 
117 MFO was normalized to lean body mass ( $\mathrm{mg} / \mathrm{min} / \mathrm{kg}$ LBM). Finishing times were obtained from 118 the official timer of the race (LiveTrail®, LiveTrail SARL, France).

\subsection{Statistical analysis}

Statistical analyses were carried out using the Statistical Package for the Social Sciences software (IBM SPSS Statistics for Windows, version 22.0, IBM Corp., Armonk, NY). Normality was checked using the Shapiro-Wilk test and all variables met normality assumptions. Possible sex differences in $\mathrm{FAT}_{\max }$ and MFO were assessed using an independent samples Student's t-test. Pearson product-moment correlations were computed to assess whether the primary outcome, race time, was associated with body composition variables (BMI, \%FM and \%LBM) and CPETderived variables $\left(\mathrm{VO}_{2}\right.$ peak, $\mathrm{V}_{\text {peak }}, \mathrm{V}_{\mathrm{VT} 1}, \mathrm{~V}_{\mathrm{VT} 2}, \% \mathrm{VT}_{1}, \% \mathrm{VT}_{2}, \mathrm{FAT}_{\max }$ and MFO). This analysis was carried out for the whole sample and for the men and women sample sets. The following criteria were adopted to interpret the magnitude of the correlations: $r \leq 0.1$, trivial; $0.1<\mathrm{r} \leq 0.3$, small; $0.3<\mathrm{r} \leq 0.5$, moderate; $0.5<\mathrm{r} \leq 0.7$, large; $0.7<\mathrm{r} \leq 0.9$, very large; and $\mathrm{r}>0.9$, almost perfect [24]. Afterwards, body composition and CPET-derived variables were entered as independent variables into a stepwise multiple regression analysis with race time as the dependent variable. This analysis was conducted on both the whole sample and the men and women sample sets. Additionally, using the percentage of winning time as a splitting variable, we divided the sample into faster and slower runners (i.e., below and above the mean value for our sample) and we also conducted the abovementioned analysis on those sample sets. Assumptions of linearity, normality, independence (Durbin-Watson statistic values were between 1.5 and 2.5), homoscedasticity and absence of collinearity (all VIF values were below 1.3) were checked in all the multiple regression analyses performed. The significance level was set at $\mathrm{p}<0.05$ and data are presented as means and standard deviations $( \pm \mathrm{SD})$. 
142

143

144

145

146

147

148

149

150

151

152

153

154

155

156

157

158

159

160

161

162

163

164

165

166

167

168

\section{Results}

From the initial sample (47 athletes), 4 participants did not start the race due to injury and 32 athletes (19 men and 13 women) successfully completed the race. The finishers/starters ratio for the subjects of the present study (i.e. $74.4 \%$ ) was similar to the ratio when all race participants were considered (73.8\%). Male athletes' average finish time was 20 h $43 \min \pm 3$ h 58 min, $174 \%$ of winning time; while females athletes' average finish time was $22 \mathrm{~h} 20 \min \pm 2 \mathrm{~h} 24 \min , 157 \%$ of winning time. All levels of performance were represented in our sample, as shown by their rank ranging from 13th to 395th place (of 397 finishers) in male category, and from 7th to 32th place (of 47 finishers) in female category. Participant characteristics, including demographic information, training and competition history and data from the cardiopulmonary exercise test, are presented in Table $\mathbf{1 .}$

\section{** Insert Table 1 and 2 near here **}

No significant sex differences were noted in $\mathrm{MFO}$ and $\mathrm{FAT}_{\max }$. Results from correlational analysis are depicted in Table 2. Both among men and women, \%FM and \%LBM were significantly and largely associated with race time. $\mathrm{V}_{\mathrm{VT} 1}$ was significantly correlated with performance in men and women, although the magnitude of the correlation was greater for the women sample set (very large vs moderate). $\mathrm{V}_{\mathrm{VT} 2}$ was significantly and very largely correlated with race time in both sexes. Conversely, neither in women nor in men \%VT1 was associated with performance; whereas $\% \mathrm{VT} 2$ was linked with race time only in the women sample set. $\mathrm{VO}_{2}$ peak was significantly correlated with performance in men and women, although the magnitude of the correlation was greater for the women sample set (very large vs large) (Figure 2). $\mathrm{V}_{\text {peak }}$ was significantly correlated with race time in both sexes, but the magnitude of the correlation was greater for the men sample set (very large vs large). Lastly, neither in women nor in men $\mathrm{FAT}_{\max }$ was associated with performance, while MFO was largely correlated with race time in both sexes (Figure 3). 
** Insert Figure 2 and 3 near here **

171

172 Results from multiple regression analysis are reported in Table 3. Considering the whole sample,

$173 \mathrm{~V}_{\mathrm{VT} 2}$ and MFO together explained $55 \%$ of the variation observed in race time (adj $\mathrm{R}^{2}=0.549$;

$\left.174 \mathrm{~F}_{2,29}=19.89 ; \mathrm{p}<0.001\right)$. For the men sample set, $\mathrm{V}_{\text {peak }}$ and MFO together explained $66 \%$ of the

175 variation observed in race time (adj $\left.\mathrm{R}^{2}=0.658 ; \mathrm{F}_{2,16}=18.32 ; \mathrm{p}<0.001\right)$. Meanwhile, for the

176 women sample set, $\mathrm{VO}_{2}$ peak was the only statistically significant variable explaining $69 \%$ of the

177 variation in race time $\left(\operatorname{adj} \mathrm{R}^{2}=0.693 ; \mathrm{F}_{1,11}=28.14 ; \mathrm{p}<0.001\right)$. Lastly, when splitting the sample

178 by relative race time, for the faster runners sample set, $\mathrm{V}_{\text {peak }}$ was the only statistically significant

179 variable explaining $75 \%$ of the variation in race time $\left(\operatorname{adj} \mathrm{R}^{2}=0.748 ; \mathrm{F}_{1,16}=47.46 ; \mathrm{p}<0.001\right)$;

180 while for the slower runners sample set, $\mathrm{VO}_{2}$ peak was the only statistically significant variable

181 explaining $33 \%$ of the variation in race time (adj $\left.\mathrm{R}^{2}=0.326 ; \mathrm{F}_{1,12}=5.77 ; \mathrm{p}=0.033\right)$.

$183 * *$ Insert Table 3 near here ** 
184

185

186

187

188

189

190

191

192

193

194

195

196

197

198

199

200

201

202

203

204

205

206

207

208

209

210

211

\section{Discussion}

The main finding of this study was that UT performance, both in men and women, was correlated with classical physiological variables of endurance running performance $\left(\mathrm{V}_{\mathrm{VT} 1}, \mathrm{~V}_{\mathrm{VT} 2}, \mathrm{~V}_{\text {peak }}\right.$ and $\mathrm{VO}_{2}$ peak), as well as with MFO and body composition factors (\%FM and \%LBM). However, multiple regression analysis indicated that $\mathrm{V}_{\mathrm{VT} 2}$ and $\mathrm{MFO}$ explained $55 \%$ of the variation observed in all participants' race times. Regarding possible sex differences, men performance was independently predicted by $\mathrm{V}_{\text {peak }}$ and MFO; while $\mathrm{VO}_{2}$ peak was the only statistically significant variable explaining the variation in women's race times. The abovementioned regression models were able to explain $66 \%$ of the variation in men performance and $69 \%$ of the variation in women performance. Lastly, the magnitude of the correlation with performance of $\mathrm{V}_{\mathrm{VT1}}$ and $\mathrm{VO}_{2}$ peak was larger among women; whereas the magnitude of the correlation with performance of $\mathrm{V}_{\text {peak }}$ was larger among men.

The significant association found between $\mathrm{VO}_{2}$ peak and performance coincides with most of previous research in the field [3, 5-7], although not all [8]. Besides, our results highlight a large association between race time and $\mathrm{V}_{\mathrm{VT} 1}$ and $\mathrm{V}_{\mathrm{VT} 2}$. This relationship contrasts with two recent studies undertook in shorter trail races (i.e., 27 and $31 \mathrm{~km}$ ), where authors found no correlation between race time and those two variables $[3,8]$. However, it is in agreement with Fornasiero et al. [7], who showed that power output at $\mathrm{VT}_{1}$ and $\mathrm{VT}_{2}(\mathrm{in} \mathrm{W} / \mathrm{kg}$ ) was associated with performance in a $65-\mathrm{km}$ trail race. Despite keeping in mind that correlation does not imply causation, our results suggest that the importance of submaximal parameters associated with exercise thresholds increases as competition length does, even though peak speed and oxygen uptake remain associated with performance in UT races.

On the other hand, in Ironman triathletes it has been shown that the relationship between MFO and performance is slightly stronger among women, as compared to men $[16,18]$. However, when $\mathrm{VO}_{2}$ peak was integrated in the analysis, the abovementioned association in women disappeared, 
212 unlike the association in men. Authors showed that VO2peak was the only independent variable 213 that predicted women performance. Our results matches with those previously published and extend it to the UT field. Moreover, as far as we are concerned, no study had previously compared the association of $\mathrm{V}_{\mathrm{VT} 1}$ with ultraendurance performance between men and women. The stronger relationship we found between race time and $\mathrm{V}_{\mathrm{VT} 1}$ in women, as compared with men, suggest it could be related with the lower absolute speed at which they performed the race. Notwithstanding, further studies in the field are required to clarify this assumption.

MFO values in our sample were largely higher than previously reported in male ultramarathon runners $(12.85 \pm 2.64 \mathrm{vs} 7.3 \pm 2.5 \mathrm{mg} / \mathrm{min} / \mathrm{kg} \mathrm{LBM})[25]$; and compared to previous studies in Ironman athletes $[16,18]$, values for male runners were also higher $(12.85 \pm 2.64$ vs $9.05 \pm 0.27$ $\mathrm{mg} / \mathrm{min} / \mathrm{kg} \mathrm{LBM})$, whereas values for female runners were slightly lower $(11.74 \pm 3.58 \mathrm{vs} 12.9 \pm$ $0.5 \mathrm{mg} / \mathrm{min} / \mathrm{kg} \mathrm{LBM})$. Interestingly, contrary to prior investigation $[15,16,18]$, our results failed to show a higher MFO for female participants compared to male participants. Overall, our UT runners seem to possess a high fat oxidative capacity. Notwithstanding, differences in CPET protocol (cycling vs running; 2-min vs 3-min stages) and time frame of testing (morning vs afternoon) are known to affect MFO [23, 26]. competitions (10-km running). Moreover, the fact that MFO appeared an independent

237 performance predictor in the multiple regression analysis when considering the whole sample and 238 the male sample set highlights the important role of fat metabolism in UT events. Considering 239 that these races are performed at a $\mathrm{HR}$ around $90 \%$ of $\mathrm{VT}_{1}$ [7], thus a moderate intensity where 
240 fat metabolism could supply a large percentage of the required energy, faster UT runners may

241 elicit higher rates of fat oxidation and/or have a greater reliance upon fat as a fuel source during

242 UT races $[15,28]$. However, a recent study has failed to show an improvement in fat metabolism

243 among recreational ultramarathon runners following either a polarized or a threshold 12-week

244 training program [25]. Therefore, further research is advocated to aid in establishing training

245 recommendations to increase fat use during UT races and thus preserve carbohydrate stores.

246 Additionally, further studies are needed to confirm whether possessing a high MFO during fasted

247 conditions translates to high rates of fat oxidation during prolonged exercise in a fed state.

249 Previous research has consistently demonstrated the importance of body composition upon trail

running performance $[3,5,7,29]$. Some studies reported an inverse relationship between $\% \mathrm{FM}$ and race time $[3,7,29]$ whereas others found a positive association between \%LBM and performance [5]. In our study both \%FM and \%LBM appeared correlated to race time. Although these relationships with performance were not independent from the other variables assessed in the study and the usage of bioelectrical impedance analysis leads us to be cautious, current results seem to reinforce previous assumptions regarding the important of body composition in trail running performance, both in male and female athletes.

The predictive strength of our performance model (55\% for the whole sample, $66 \%$ for the men sample set and $69 \%$ for the women sample set) matches Fornasiero et al. [7] results in a $65-\mathrm{km}$ trail race, but it is lower than those previously reported in shorter trail running races (between 27 and $31 \mathrm{~km})[3,6,8]$. Consequently, it could be argued that finishing times are less predictable from laboratory variables in UT races as compared with shorter trail running races. Nevertheless, although our study was performed on a larger sample (even when considering men and women sample sets) than most of previous studies in the field, the sample was not yet large enough to

265 draw robust conclusions and further studies are required to confirm our results. In addition, we 266 acknowledge that additional neuromuscular factors (isometric strength, local endurance strength 267 or downhill running ability) could improve the predictive strength of the proposed UT 
268 performance model [4, 6, 30]. Even more, as previously suggested, in UT races factors difficult

269 to objectively measure such as mental toughness or avoidance of gastrointestinal symptoms

270 probably play a relevant role in determining the final result [11].

271

272 There are some limitations in our study that should be acknowledged. Although participants were

273 asked to attend the laboratory for the cardiopulmonary exercise test with at least $6 \mathrm{~h}$ of fasting,

274 we do not record fasting times of each participant and we recognize that differences in the length

275 of fast may have impacted estimates of MFO and $\mathrm{FAT}_{\max }$. It is also acknowledged that testing in

276 a fasted state may entail a limitation to the study design as UT races are performed in fed state.

277 Notwithstanding, as it is known that exogenous carbohydrate uptake cannot match utilization

278 rates during prolonged endurance exercise, running with low carbohydrate availability is not an

279 uncommon situation in the final stages of UT races. Lastly, we must recognize that the results are

280 based on a single race with its own characteristics (race profile, terrain, etc.) and cannot be

281 generalized to any UT race. This fact jointly with sample size prevent us from establishing a

282 robust UT performance model (especially when considering sex specific models). 
283

284

285

286

287

288

289

290

291

292

293

294

295

296

297

298

299

300

301

302

\section{Conclusions}

Although the nature of the study and the sample size lead us to be cautious in reaching definitive conclusions, maximal fat oxidation appears to be an important determinant of final race time in UT competitions. At the same time, peak speed and submaximal speeds associated with exercise thresholds, maximal aerobic capacity $\left(\mathrm{VO}_{2}\right.$ peak), and body composition (percentage of fat mass and lean body mass) are also linked to performance in those races. Moreover, in male athletes, maximal fat oxidation is associated with race time independently of the classical physiological variables of endurance running performance; while maximal aerobic capacity and $\mathrm{V}_{\mathrm{VT} 1}$ seem to be stronger performance predictors among female athletes.

Therefore, current results support that UT coaches should undertake training strategies to upregulate fat oxidation during submaximal exercise and include workouts aimed both at improving submaximal $\left(\mathrm{V}_{\mathrm{VT} 1}\right.$ and $\left.\mathrm{V}_{\mathrm{VT} 2}\right)$ and maximal $\left(\mathrm{V}_{\text {peak }}\right.$ and $\mathrm{VO}_{2}$ peak) capacities. In a similar way, clinicians are encouraged to assess fat metabolism, as well as $\mathrm{VO}_{2}$ peak and ventilatory thresholds, when performing CPET in ultraendurance athletes. Further research is needed in order to establish the mechanisms responsible for training-induced changes in MFO. Future studies should also look into additional variables that could have an impact on UT performance, and investigate whether the application of the abovementioned training strategies improve athletes' performance in UT races. 
303

304

305

306

307

308

309

310

311

312

313

314

315

316

317

318

319

320

321

322

323

324

325

326

327

328

329

330

\section{References}

1. Knechtle B, Nikolaidis PT. Physiology and Pathophysiology in Ultra-Marathon Running. Front Physiol 2018; 9: 634. doi:10.3389/fphys.2018.00634

2. Scheer V, Basset P, Giovanelli N et al. Defining Off-road Running: A Position Statement from the Ultra Sports Science Foundation. Int J Sports Med 2020. doi:10.1055/a-10960980. doi:10.1055/a-1096-0980

3. Alvero-Cruz JR, Parent Mathias V, Garcia Romero J et al. Prediction of Performance in a Short Trail Running Race: The Role of Body Composition. Front Physiol 2019; 10: 1306. doi:10.3389/fphys.2019.01306

4. Balducci P, Clemencon M, Trama R et al. Performance Factors in a Mountain Ultramarathon. Int J Sports Med 2017; 38: 819-826. doi:10.1055/s-0043-112342

5. Bjorklund G, Swaren M, Born DP et al. Biomechanical Adaptations and Performance Indicators in Short Trail Running. Front Physiol 2019; 10: 506. doi:10.3389/fphys.2019.00506

6. Ehrstrom S, Tartaruga MP, Easthope CS et al. Short Trail Running Race: Beyond the Classic Model for Endurance Running Performance. Med Sci Sports Exerc 2018; 50: 580-588. doi:10.1249/MSS.0000000000001467

7. Fornasiero A, Savoldelli A, Fruet D et al. Physiological intensity profile, exercise load and performance predictors of a 65-km mountain ultra-marathon. J Sports Sci 2018; 36: 1287-1295. doi:10.1080/02640414.2017.1374707

8. Scheer V, Janssen TI, Vieluf S et al. Predicting Trail Running Performance With Laboratory Exercise Tests and Field Based Results. Int J Sports Physiol Perform 2018. doi:10.1123/ijspp.2018-0390: 1-13. doi:10.1123/ijspp.2018-0390

9. di Prampero PE, Atchou G, Bruckner JC et al. The energetics of endurance running. European journal of applied physiology and occupational physiology 1986; 55: 259-266

10. O'Loughlin E, Nikolaidis PT, Rosemann T et al. Different Predictor Variables for Women and Men in Ultra-Marathon Running-The Wellington Urban Ultramarathon 2018. 
International journal of environmental research and public health 2019; 16. doi:10.3390/ijerph16101844

11. Millet GY, Hoffman MD, Morin JB. Sacrificing economy to improve running performance--a reality in the ultramarathon? J Appl Physiol 2012; 113: 507-509. doi:10.1152/japplphysiol.00016.2012

12. Vernillo G, Millet GP, Millet GY. Does the Running Economy Really Increase after Ultra-Marathons? Front Physiol 2017; 8: 783. doi:10.3389/fphys.2017.00783

13. Lazzer S, Salvadego D, Taboga P et al. Effects of the Etna uphill ultramarathon on energy cost and mechanics of running. Int J Sports Physiol Perform 2015; 10: 238-247. doi:10.1123/ijspp.2014-0057

14. Beck ON, Kipp S, Byrnes WC et al. Use aerobic energy expenditure instead of oxygen uptake to quantify exercise intensity and predict endurance performance. J Appl Physiol (1985) 2018; 125: 672-674. doi:10.1152/japplphysiol.00940.2017

15. Maunder E, Plews DJ, Kilding AE. Contextualising Maximal Fat Oxidation During Exercise: Determinants and Normative Values. Front Physiol 2018; 9: 599. doi:10.3389/fphys.2018.00599

16. Frandsen J, Vest SD, Larsen S et al. Maximal Fat Oxidation is Related to Performance in an Ironman Triathlon. International journal of sports medicine 2017. doi:10.1055/s-0043117178. doi:10.1055/s-0043-117178

17. Maunder E, Kilding AE, Plews DJ. Substrate Metabolism During Ironman Triathlon: Different Horses on the Same Courses. Sports Med 2018; 48: 2219-2226. doi:10.1007/s40279-018-0938-9

18. Vest SD, Frandsen J, Larsen S et al. Peak Fat Oxidation is not Independently Related to Ironman Performance in Women. Int J Sports Med 2018; 39: 916-923. doi:10.1055/a0660-0031

19. Harriss DJ, MacSween A, Atkinson G. Ethical Standards in Sport and Exercise Science Research: 2020 Update. Int J Sports Med 2019; 40: 813-817. doi:10.1055/a-1015-3123 
358 20. Rietjens GJ, Kuipers H, Kester AD et al. Validation of a computerized metabolic 359 measurement system (Oxycon-Pro) during low and high intensity exercise. Int J Sports 360

21. Skinner JS, McLellan TM. The transition from aerobic to anaerobic metabolism. Res Q 362

22. Frayn KN. Calculation of substrate oxidation rates in vivo from gaseous exchange. Journal of applied physiology: respiratory, environmental and exercise physiology 1983; 55: 628-634. doi:10.1152/jappl.1983.55.2.628

23. Amaro-Gahete FJ, Sanchez-Delgado G, Jurado-Fasoli L et al. Assessment of maximal fat oxidation during exercise: A systematic review. Scand J Med Sci Sports 2019; 29: 910921. doi:10.1111/sms.13424

24. Thomas J, Nelson J, Silverman S. Research Methods in Physical Activity. Champaign: Human Kinetics; 2005

25. Perez A, Ramos-Campo DJ, Marin-Pagan C et al. Impact of Polarized Versus Threshold Training on Fat Metabolism and Neuromuscular Variables in Ultrarunners. Int J Sports Physiol Perform 2019. doi:10.1123/ijspp.2019-0113: 1-8. doi:10.1123/ijspp.2019-0113

26. Amaro-Gahete FJ, Jurado-Fasoli L, Trivino AR et al. Diurnal Variation of Maximal FatOxidation Rate in Trained Male Athletes. Int J Sports Physiol Perform 2019; 14: 11401146. doi:10.1123/ijspp.2018-0854

27. Lima-Silva AE, Bertuzzi RC, Pires FO et al. Relationship between training status and maximal fat oxidation rate. J Sports Sci Med 2010; 9: 31-35

28. Dandanell S, Meinild-Lundby AK, Andersen AB et al. Determinants of maximal wholebody fat oxidation in elite cross-country skiers: Role of skeletal muscle mitochondria. Scand J Med Sci Sports 2018; 28: 2494-2504. doi:10.1111/sms.13298

29. Hoffman MD, Lebus DK, Ganong AC et al. Body composition of 161-km ultramarathoners. Int J Sports Med 2010; 31: 106-109. doi:10.1055/s-0029-1241863 
384 30. Giandolini M, Horvais N, Rossi $\mathrm{J}$ et al. Acute and delayed peripheral and central 385 neuromuscular alterations induced by a short and intense downhill trail run. Scand J Med Sci Sports 2016; 26: 1321-1333. doi:10.1111/sms.12583 


\section{$387 \quad$ Figure legend}

388

389 Figure 1. Altitude profile of the race including aid stations (reproduced with permission from

390 race organization)

391

392 Figure 2. Relationship between race time and peak oxygen uptake $\left(\mathrm{VO}_{2}\right.$ peak).

393 Men results are depicted in full circles and women results in empty circles

394

395 Figure 3. Relationship between race time and maximal fat oxidation (MFO).

396 Men results are depicted in full circles and women results in empty circles

397

$398 \quad \underline{\text { Table legend }}$

399

400 Table 1. Sample main characteristics $($ mean \pm SD)

401

402 Table 2. Results from correlational analysis

403

404 Table 3. Model summary resulting from stepwise multiple regression analyses 


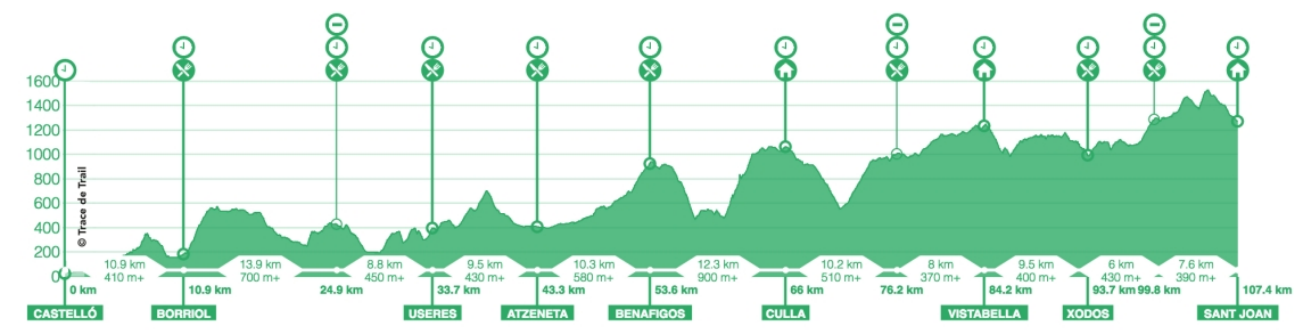

Figure 1. Altitude profile of the race including aid stations (reproduced with permission from race organization) 


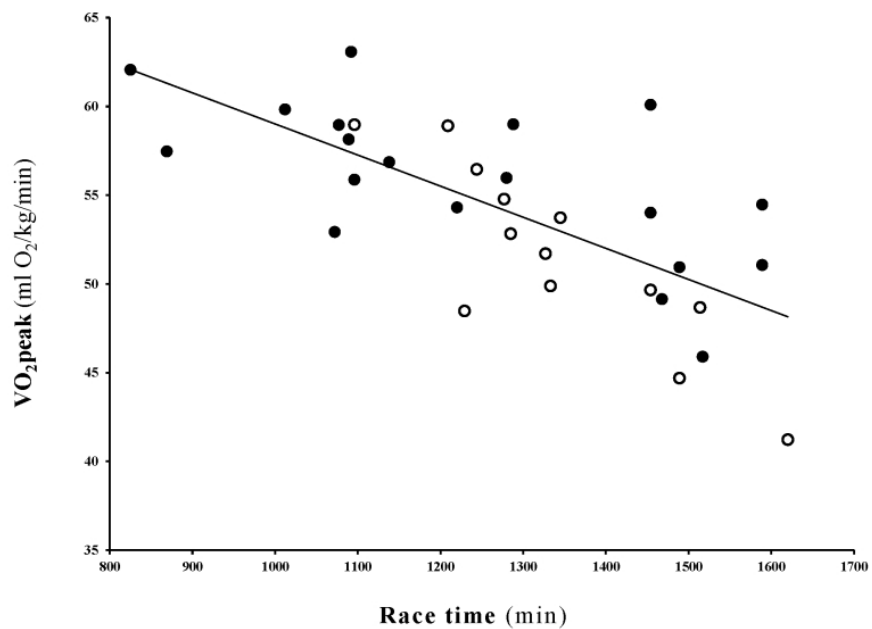

Figure 2. Relationship between race time and peak oxygen uptake (VO2peak). Men results are depicted in full circles and women results in empty circles

$$
221 \times 312 \mathrm{~mm}(300 \times 300 \text { DPI) }
$$


Figure 3. Relationship between race time and maximal fat oxidation (MFO). Men results are depicted in full circles and women results in empty circles

$221 \times 312 \mathrm{~mm}(300 \times 300$ DPI $)$ 
Table 1. Sample main characteristics $($ mean $\pm \mathrm{SD})$

\begin{tabular}{|c|c|c|c|}
\hline & $\begin{array}{c}\text { All sample } \\
(\mathrm{n}=32)\end{array}$ & $\begin{array}{c}\text { Males } \\
(n=19)\end{array}$ & $\begin{array}{l}\text { Females } \\
(\mathrm{n}=13)\end{array}$ \\
\hline Age (years) & $41 \pm 6$ & $40 \pm 5$ & $42 \pm 6$ \\
\hline Number of years running & $8 \pm 3$ & $8 \pm 2$ & $8 \pm 3$ \\
\hline Number of races $>100 \mathrm{~km}$ & $2 \pm 3$ & $2 \pm 3$ & $2 \pm 4$ \\
\hline Weekly training days & $5 \pm 1$ & $5 \pm 1$ & $5 \pm 1$ \\
\hline Weekly running volume (km) & $70 \pm 22$ & $76 \pm 25$ & $61 \pm 13$ \\
\hline Weekly positive elevation (m) & $1772 \pm 691$ & $1868 \pm 765$ & $1631 \pm 565$ \\
\hline Weekly training hours & $10 \pm 4$ & $10 \pm 4$ & $9 \pm 5$ \\
\hline Strength training (\%) & $81.3 \%$ & $73.7 \%$ & $92.3 \%$ \\
\hline BMI $\left(\mathrm{kg} / \mathrm{m}^{2}\right)$ & $22.8 \pm 2$ & $23.6 \pm 1.6$ & $21.7 \pm 2$ \\
\hline FM $(\%)$ & $15.4 \pm 4.9$ & $12.9 \pm 3.5$ & $19.1 \pm 4.5$ \\
\hline LBM (\%) & $80.3 \pm 4.7$ & $82.7 \pm 3.4$ & $76.8 \pm 4.4$ \\
\hline $\mathbf{V}_{\text {VT1 }}(\mathrm{km} / \mathrm{h})$ & $10.8 \pm 1.2$ & $1.2 \pm 1.1$ & $10.1 \pm 0.9$ \\
\hline $\mathbf{O V T}_{\mathbf{1}}\left(\% \mathrm{VO}_{2}\right.$ peak $)$ & $71.9 \pm 5.4$ & $71.8 \pm 6.1$ & $72.1 \pm 4.4$ \\
\hline $\mathbf{V}_{\text {VT2 }}(\mathrm{km} / \mathrm{h})$ & $13.3 \pm 1.4$ & $13.8 \pm 1.2$ & $12.5 \pm 1.3$ \\
\hline $\mathbf{\%} \mathbf{V T}_{\mathbf{2}}\left(\% \mathrm{VO}_{2}\right.$ peak $)$ & $85.6 \pm 5.3$ & $85.3 \pm 4.7$ & $86.1 \pm 6.2$ \\
\hline $\mathbf{V O}_{2}$ peak $\left(\mathrm{ml} \mathrm{O}_{2} / \mathrm{kg} / \mathrm{min}\right)$ & $54.1 \pm 5.2$ & $55.8 \pm 4.5$ & $51.5 \pm 5.2$ \\
\hline $\mathbf{V}_{\text {peak }}(\mathrm{km} / \mathrm{h})$ & $15.9 \pm 1.9$ & $16.9 \pm 1.5$ & $14.4 \pm 1.4$ \\
\hline $\mathbf{F A T}_{\max }\left(\% \mathrm{VO}_{2}\right.$ peak $)$ & $64.3 \pm 9.4$ & $64.9 \pm 10.7$ & $63.4 \pm 7.3$ \\
\hline MFO (mg/min/kg LBM) & $12.4 \pm 3.1$ & $12.9 \pm 2.6$ & $11.7 \pm 3.6$ \\
\hline
\end{tabular}

Abbreviations: Strength training (\%), percentage of participants who performed at least one weekly lower-limb strength training in the previous 3 months; BMI, Body mass index; FM, fat mass; LBM, lean body mass; $\mathrm{V}_{\mathrm{VT} 1}$, speed at the first ventilatory threshold; $\% \mathrm{VT}_{1}$, percentage of $\mathrm{VO}_{2}$ peak at the first 
ventilatory threshold; $\mathrm{V}_{\mathrm{VT} 2}$, speed at the second ventilatory threshold; $\% \mathrm{VT}_{2}$, percentage of $\mathrm{VO}_{2}$ peak at the second ventilatory threshold; $\mathrm{VO}_{2}$ peak, peak oxygen uptake; $\mathrm{V}_{\text {peak }}$, peak speed reached at the CPET; $\mathrm{FAT}_{\max }$, exercise intensity eliciting MFO; MFO, maximal fat oxidation. 
Table 2. Results from correlational analysis

\begin{tabular}{|c|c|c|c|}
\hline & \multicolumn{3}{|c|}{ Correlation with race time $(\mathrm{r} / p)$} \\
\hline & $\begin{array}{l}\text { All sample } \\
\quad(\mathrm{n}=32)\end{array}$ & $\begin{array}{c}\text { Men } \\
(n=19)\end{array}$ & $\begin{array}{l}\text { Women } \\
(\mathrm{n}=13)\end{array}$ \\
\hline BMI $\left(\mathrm{kg} / \mathrm{m}^{2}\right)$ & $0.253 / 0.163$ & $0.482 / 0.037$ & $0.523 / 0.066$ \\
\hline FM $(\%)$ & $0.575 / 0.001$ & $0.577 / 0.010$ & $0.618 / 0.024$ \\
\hline LBM (\%) & $-0.586 /<0.001$ & $-0.608 / 0.006$ & $-0.612 / 0.026$ \\
\hline $\mathbf{V}_{\text {VT1 }}(\mathrm{km} / \mathrm{h})$ & $-0.579 / 0.001$ & $-0.486 / 0.035$ & $\mathbf{- 0 . 7 5 7 / 0 . 0 0 3}$ \\
\hline $\mathbf{\% V T}_{\mathbf{1}}\left(\% \mathrm{VO}_{2}\right.$ peak $)$ & $-0.199 / 0.275$ & $-0.148 / 0.547$ & $-0.526 / 0.065$ \\
\hline $\mathbf{V}_{\text {VT2 }}(\mathrm{km} / \mathrm{h})$ & $-0.717 /<0.001$ & $-0.730 /<0.001$ & $-0.755 / 0.003$ \\
\hline $\mathbf{\%} \mathbf{V T}_{\mathbf{2}}\left(\% \mathrm{VO}_{2}\right.$ peak $)$ & $-0.393 / 0.026$ & $-0.408 / 0.083$ & $-0.652 / 0.016$ \\
\hline $\mathbf{V O}_{2}$ peak $\left(\mathrm{ml} \mathrm{O}_{2} / \mathrm{kg} / \mathrm{min}\right)$ & $-0.670 /<0.001$ & $-0.629 / 0.004$ & $-0.848 /<0.001$ \\
\hline $\mathbf{V}_{\text {peak }}(\mathrm{km} / \mathrm{h})$ & $-0.693 /<0.001$ & $-0.743 /<0.001$ & $-0.692 / 0.009$ \\
\hline $\mathbf{F A T}_{\max }\left(\% \mathrm{VO}_{2}\right.$ peak $)$ & $0.195 / 0.285$ & $0.353 / 0.138$ & $0.344 / 0.250$ \\
\hline MFO (mg/min $/ \mathrm{kg}$ LBM) & $-0.538 / 0.001$ & $-0.530 / 0.019$ & $-0.592 / 0.033$ \\
\hline
\end{tabular}

Abbreviations: BMI, Body mass index; FM, fat mass; LBM, lean body mass; $\mathrm{V}_{\mathrm{VT} 1}$, speed at the first ventilatory threshold; $\% \mathrm{VT}_{1}$, percentage of $\mathrm{VO}_{2}$ peak at the first ventilatory threshold; $\mathrm{V}_{\mathrm{VT} 2}$, speed at the second ventilatory threshold; $\% \mathrm{VT}_{2}$, percentage of $\mathrm{VO}_{2}$ peak at the second ventilatory threshold; $\mathrm{VO}_{2}$ peak, peak oxygen uptake; $\mathrm{V}_{\text {peak }}$, peak speed reached at the CPET; $\mathrm{FAT}_{\max }$, exercise intensity eliciting MFO; MFO, maximal fat oxidation. 
Table 3. Model summary resulting from stepwise multiple regression analyses

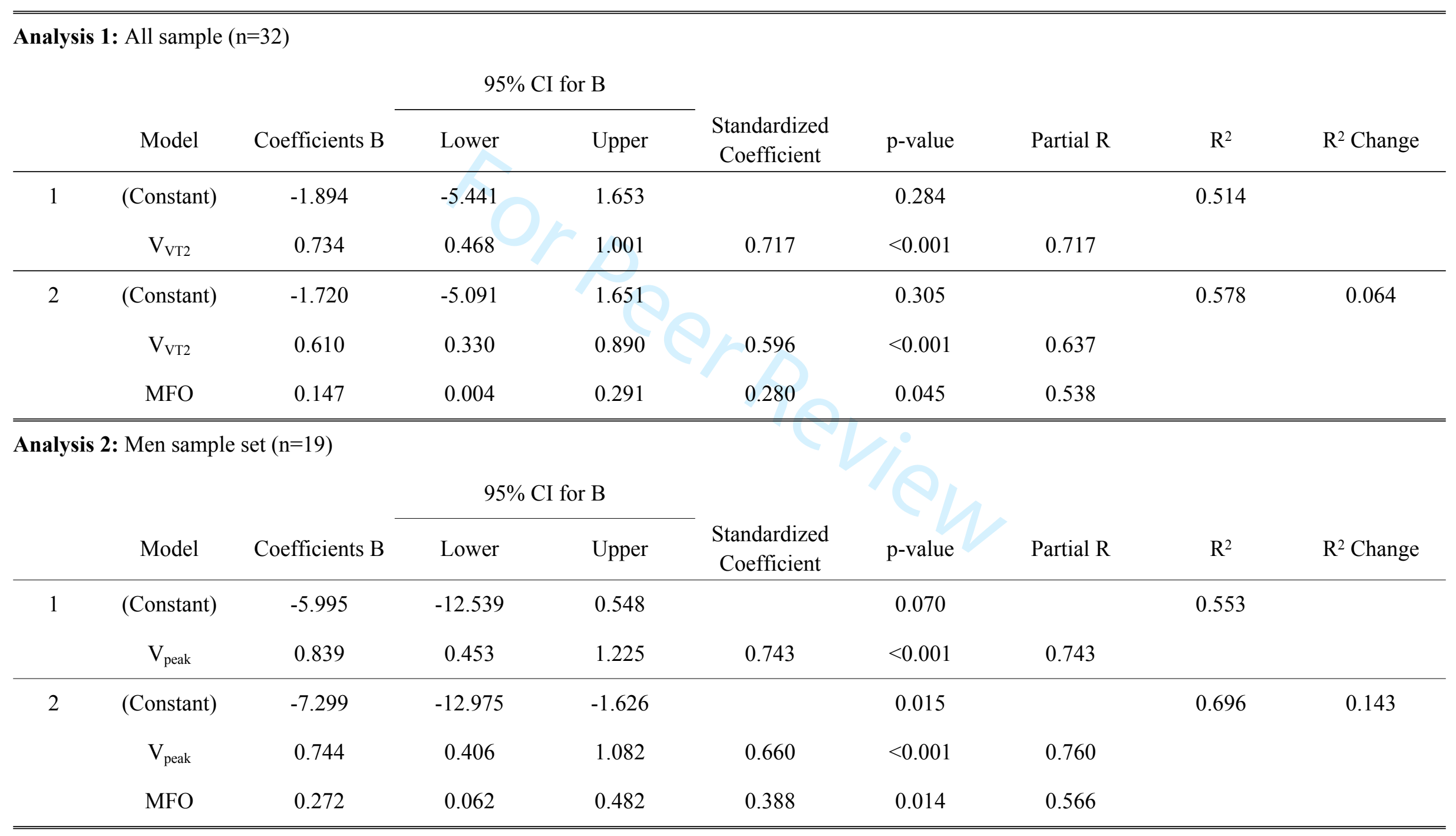




\begin{tabular}{|c|c|c|c|c|c|c|c|c|c|}
\hline \multicolumn{10}{|c|}{ Analysis 3: Women sample set $(\mathrm{n}=13)$} \\
\hline & \multirow[b]{2}{*}{ Model } & \multirow[b]{2}{*}{ Coefficients B } & \multicolumn{2}{|c|}{$95 \% \mathrm{CI}$ for $\mathrm{B}$} & \multirow[b]{2}{*}{$\begin{array}{c}\text { Standardized } \\
\text { Coefficient }\end{array}$} & \multirow[b]{2}{*}{ p-value } & \multirow[b]{2}{*}{ Partial R } & \multirow[b]{2}{*}{$\mathrm{R}^{2}$} & \multirow[b]{2}{*}{$\mathrm{R}^{2}$ Change } \\
\hline & & & Lower & Upper & & & & & \\
\hline \multirow[t]{2}{*}{1} & (Constant) & 0.836 & -1.891 & 3.562 & & 0.514 & & 0.719 & \\
\hline & $\mathrm{VO}_{2}$ peak & 0.127 & 0.074 & 0.180 & 0.848 & $<0.001$ & 0.848 & & \\
\hline
\end{tabular}

Analysis 4: Faster runners sample set $(\mathrm{n}=18)$

\begin{tabular}{|c|c|c|c|c|c|c|c|c|c|}
\hline & \multirow[b]{2}{*}{ Model } & \multirow[b]{2}{*}{ Coefficients B } & \multicolumn{2}{|c|}{$95 \%$ CI for B } & \multirow[b]{2}{*}{$\begin{array}{c}\text { Standardized } \\
\text { Coefficient }\end{array}$} & \multirow[b]{2}{*}{ p-value } & \multirow[b]{2}{*}{ Partial R } & \multirow[b]{2}{*}{$\mathrm{R}^{2}$} & \multirow[b]{2}{*}{$\mathrm{R}^{2}$ Change } \\
\hline & & & Lower & Upper & & & & & \\
\hline \multirow[t]{2}{*}{1} & (Constant) & -2.493 & -5.952 & 0.966 & & 0.146 & & 0.748 & \\
\hline & $V_{\text {peak }}$ & 0.681 & 0.471 & 0.890 & 0.865 & $<0.001$ & 0.865 & & \\
\hline
\end{tabular}

Analysis 5: Slower runners sample set $(n=14)$

\begin{tabular}{|c|c|c|c|c|c|c|c|c|c|}
\hline & \multirow[b]{2}{*}{ Model } & \multirow[b]{2}{*}{ Coefficients B } & \multicolumn{2}{|c|}{$95 \% \mathrm{CI}$ for $\mathrm{B}$} & \multirow[b]{2}{*}{$\begin{array}{c}\text { Standardized } \\
\text { Coefficient }\end{array}$} & \multirow[b]{2}{*}{$\mathrm{p}$-value } & \multirow[b]{2}{*}{ Partial R } & \multirow[b]{2}{*}{$\mathrm{R}^{2}$} & \multirow[b]{2}{*}{$\mathrm{R}^{2}$ Change } \\
\hline & & & Lower & Upper & & & & & \\
\hline \multirow[t]{2}{*}{1} & (Constant) & 3.510 & 0.556 & 6.464 & & 0.024 & & 0.325 & \\
\hline & $\mathrm{VO}_{2}$ peak & 0.063 & 0.006 & 0.120 & 0.570 & 0.033 & 0.570 & & \\
\hline
\end{tabular}

Abbreviations: $\mathrm{V}_{\mathrm{VT} 2}$, speed at the second ventilatory threshold; $\mathrm{MFO}$, maximal fat oxidation; $\mathrm{V}_{\text {peak }}$, peak speed reached at the $\mathrm{CPET}$; $\mathrm{VO}_{2}$ peak, peak oxygen uptake. 